\title{
From guidelines to the sidelines: implementation of cardiovascular preparticipation evaluation in sports clubs is lagging.
}

Kristofer Hedman, Sofia Sunnerud, Anna Carlén, Magnus Janzon and Eva Nylander

The self-archived postprint version of this journal article is available at Linköping University Institutional Repository (DiVA):

http://urn.kb.se/resolve?urn=urn:nbn:se:liu:diva-152136

N.B.: When citing this work, cite the original publication.

Hedman, K., Sunnerud, S., Carlén, A., Janzon, M., Nylander, E., (2019), From guidelines to the sidelines: implementation of cardiovascular preparticipation evaluation in sports clubs is lagging., British Journal of Sports Medicine, 53(1), 3-4. https://doi.org/10.1136/bjsports-2018-099297

Original publication available at:

https://doi.org/10.1136/bjsports-2018-099297

Copyright: BMJ Publishing Group

http://group.bmj.com/ 
TITLE

From guidelines to the sidelines - implementation of cardiovascular pre-participation evaluation in sports clubs is lagging

\section{AUTHORS}

Kristofer Hedman ${ }^{1}$, Sofia Sunnerud ${ }^{2}$, Anna Carlén ${ }^{1}$, Magnus Janzon $^{2}$, Eva Nylander ${ }^{1}$

1) Department of Clinical Physiology and Department of Medical and Health Sciences, Linköping University, Linköping, Sweden.

2) Department of Cardiology and Department of Medical and Health Sciences, Linköping University, Linköping, Sweden.

\section{CORRESPONDING AUTHOR}

Kristofer Hedman, Department of Clinical Physiology, Linköping University Hospital, Linköping, Sweden +4670 4897941, kristofer.hedman@liu.se 
In the last years, European and American organisations have presented rigorous position statements for guidance of physicians engaged in the cardiovascular screening of athletes as part of a pre-participation evaluation (PPE).[1,2] In addition, continuous improvements of criteria for electrocardiogram (ECG) interpretation in athletes over the last decade have yielded comprehensive updated international guidelines.[3] Thus, the stage should be set for an evidence-based, best practice cardiovascular PPE for the benefit of all competitive athletes included under each country's or sports governing body's regulations and recommendations. However, as pointed out in last year's position statement from the American Medical Society for Sports Medicine,[2] the long-standing debate regarding the inclusion or not of ECG in cardiovascular screening may have halted or clouded other important discussions and progress in the field. We believe one issue that has received far too little attention is the question of actual implementation of the cardiovascular PPE in sports clubs.

Notably, several reports from the United States have found an inadequate implementation or awareness of PPE recommendations.[4, 5, 6] For example, in 2013 in this journal, Madsen et al. reported results from a survey directed to pediatricians, family physicians and athletic directors.[4] They found not only a poor compliance to the American Heart Association PPE recommendations, but also lack of awareness and knowledge regarding the recommendations. How well the cardiovascular PPE is implemented outside of the United States is largely unknown.

\section{CARDIOVASCULAR PPE IN SWEDEN}

The PPE is non-mandatory for sports participation in Sweden, but recommendations from the Swedish Sports Confederation dictate that all elite athletes aged 16-35 years or athletes belonging to a sports high school should at least once every second year undergo cardiovascular screening, including a resting ECG. The concept of elite is to be defined by each specific sports federation (e.g. Swedish Football Federation) 
and is in general associated with the level of competition at a national or international level. In Sweden, the PPE is performed outside the public healthcare system and the responsibility (and financing) of conducting PPE is divided between the sports club, the specific sports federation or the sports high school. Athletes with abnormal findings meriting for further investigation are referred to the public health care system.

We recently addressed an electronic survey to sports clubs with elite level athletes in one out of 21 geographical districts of the Swedish Sports Confederation. Our aims were (a) to investigate the adherence to current recommendations, (b) to find factors associated with committing to the recommendations and (c) inquire possible reasons for not performing a cardiovascular PPE. While our results are reported in detail elsewhere,[7] in brief, only four out of $22(18 \%)$ responding sports clubs with elite athletes followed the recommendations. These four clubs were all engaged in team sports, had a team physician and all had $>10$ elite athletes. The two most common reported reasons for not performing a cardiovascular screening were either a lack of knowledge in (a) the existence of recommendations or (b) how to actually conduct the PPE. A majority of either of these two responses came from sports clubs not having a team physician.

Important limitations in our survey were the unknown response frequency and broader representation across the country, which in turn highlights the lack of a regional or national Swedish registry of sports clubs that currently have elite level athletes.

\section{FUTURE PERSPECTIVES}

Our results, and others, should not be taken as an argument for implementing universal or mandatory screening of athletes, which is another debate beyond the scope of this editorial.[8] While it may be utopic to expect uniform cardiovascular PPE implementation, it is problematic when current recommendations 
are neglected, misinterpreted or simply unknown by those responsible for the initiation of the cardiovascular PPE of athletes.

Thus, a knowledge gap clearly needs to be overcome. This requires education of physicians (of different medical specialties) and the sports community including governing bodies and sports clubs. For the community of sports cardiology, the responsibility cannot end when new guidelines, position statements and updated recommendations are published, but should rather be seen as a starting point for the next part of the work - education and conveying the message. In this aspect, we believe that we can do better!

In summary, there is a need for positive examples of the successful implementation of the cardiovascular PPE. We hereby call out for more systematic evaluations of current adherence to recommendations and, optimally, evidence-based ways to increase the level of adherence. These should be used as inspiration to help transfer knowledge from the guidelines to the sidelines.

\section{REFERENCES}

1. Mont L, Pelliccia A, Sharma S, et al. Pre-participation cardiovascular evaluation for athletic participants to prevent sudden death: Position paper from the EHRA and the EACPR, branches of the ESC. Endorsed by APHRS, HRS, and SOLAECE. Eur J Prev Cardiol 2017;24:41-69.

2. Drezner JA, O'Connor FG, Harmon KG, et al. AMSSM Position Statement on Cardiovascular Preparticipation Screening in Athletes: Current evidence, knowledge gaps, recommendations and future directions. Br J Sports Med 2017;51:153-67.

3. Drezner JA, Sharma S, Baggish A, et al. International criteria for electrocardiographic interpretation in athletes: consensus statement. Br J Sports Med 2017;51:704-31.

4. Madsen NL, Drezner JA, Jack CS. Sudden cardiac death screening in adolescent athletes: an evaluation of compliance with national guidelines. Br J Sports Med 2013;47:172-77. 
5. Caswell SV, Cortes N, Chabolla M, et al. State-Specific Differences in School Sports Preparticipation Physical Evaluation Policies. Pediatrics 2015;135:26-32.

6. Charboneau ML, Mencias T, Hoch AZ. Cardiovascular Screening Practices in Collegiate StudentAthletes. PM R 2014;6:583-6.

7. Sunnerud S, Nylander $E$, Janzon $M$, et al. Låg följsamhet till rekommenderad hjärtscreening av elitidrottare - Lägesanalys i Östergötland. Läkartidningen 2018;115.

8. Mackie A. Screening of competitive athletes to prevent sudden death: Think twice. Heart 2013;99:306-7. 